\title{
Technical Research of Iron and Steel Production
}

\author{
By Tadao Sato**
}

Splendid progress and developments have been experienced in the recent technical research of iron and steel production in Japan. Who could have imagined the prosperity of today 16 years after the War, while standing in the devastation at the moment of the defeat? However, when we reflect on these past 16 years and reconsider on what path the present developments have been achieved and from what research they have been obtained, and when we consider the future direction of technical research of iron and steel production in Japan, we are obliged to point out a number of problematical points left unsolved as yet.

The demand for iron and steel calls for the development of iron and steel techniques and requires expansion of production equipment which in turn increases the demand for iron and steel. This favorable recycling action is supposed to be the recent major trend. However, can we say that such novel steel techniques and such splendid equipment with high capacity have been completely devised by Japanese researchers and engineers? For example, a factor that has brought epoch making developments in pig iron making techniques presumably is the technique of pretreatment of raw materials to be charged into blast furnaces. In addition, an evolution of steelmaking techniques is supposed to have originated from oxygen blowing. However, all these were really originated and developed in other countries. Now, at a time when Japan must participate in the field of free economic competition and fight for technical superiority, what shall be her attitude on research?

The usual process in every research problem consists of taking empirically known phenomena and analysing them into some component factors. Each factor is then pursued theoretically and moreover some relationships among such factors are induced and verified. This research is called theoretical or fundamental study. There are very few fundamental research projects connected to techniques that can bear fruit. Nevertheless, fundamental research is eventually the prime mover which propels techniques.

Technical research is a study of the means to produce actual "goods." The final purpose of technical research is the rationalization or the development of a production process. The usual procedure in technical research is to collect and to synthesize the particular results obtained by theoretical or fundamental research and to invent or to develop a new production method that can achieve full effects from technical and economic viewpoints. In other words, the fundamental research in technology is an analysis of techniques and the technical research is a synthesis of results of fundamental research in engineering.

Based on the technique composed of collection and synthesis of results of fundamental research in engineering, the production is promoted. Besides, rationalization and development of production are performed by theoretical and fundamental analysis of techniques. Renovation of techniques is made possible by the development of fundamental theories. Moreover, only when a new technique is born and transferred to production, can the results of theoretical and fundamental research first contribute to industry.

Recently there has been a call for the promotion of fundamental studies and equipment for technical research corresponding to the technical renovation which has been expanded remarkably. In either case, the fundamental studies and technical research must proceed in parallel for the sake of effectiveness.

As previously mentioned, technical research must be a synthesis of results of fundamental studies. A synthesis is first possible only after phenomena have been analysed and the results of theoretical studies have been collected.

The fundamental research in technology is an analysis with the expectation for such synthesis. The research, in which the degree of analysis in fundamental technological studies is further enhanced, may be called "fundamental scientific studies." The theme of fundamental technological studies presupposes the formation of a technique by synthesis of their results. On the contrary, the theme of fundamental scientific research does not necessarily require such a presupposition. The results expected in fundamental scientific research are an invention cultivating entirely unknown fields, and not an immediate contribution to actual production techniques. In consequence, although the results will be finally connected with production techniques, the fundamental scientific studies must proceed in a very roundabout way. This fact must be realized.

Important research results which promote development of a really novel technique in iron and steel production should be recognized first as the results of perfected research only when (1) results of a number of excellent fundamental scientific research projects have been obtained; (2) among such results, some would have been incorporated into the fundamental technological 
studies for bearing fruit; (3) results of technical research are derived from collection and synthesis of a number of fundamental technological studies; (4) further, based on these results of technical research, another technical study is made on experimental and semi-industrial scale; and (5) through this semi-industrial stage, a prospect for Economic returns must be confirmed.

Lacking any one of the five processes, the research would not be complete. So that these processes may be successively and effectively achieved, it is further necessary for the respective engineers working on related processes to have the capacity for understanding the research results of the other projects and digesting them completely. Unless such conditions are met, research of respective processes would be performed independently with no liaison and thus the final purpose would not be achieved, because no progress would be made in the research of each process in itself. What is the present situation in Japan?

Let us follow the development of a number of new techniques for iron and steel production developed recently in Japan. Among them are the pure-oxygen top-blown converter process, vacuum melting and casting, continuous casting, hot extrusion, continuous rolling and the 20-high rolling mill. The first through third stages of research process mentioned previously for the majority of these techniques had been performed mostly in foreign countries. The techniques were imported into Japan on their fourth or fifth stages in terms of technical cooperation or technical introduction. Beyond these stages, some of these techniques proceeded up to acquisition of economic returns, while some are now under intensive research in order to attain to these stages.

This fact reveals either that the results of the research done by Japanese in the aforementioned (1) to (3) stages have been hidden in the shade, or that scarce importance has been attributed to them, or that the results of the research in such stages have not been achieved, or that researchers working on stages (1) to (3) have not enjoyed an opportunity to direct or indirect participation in the development of their research results up to production techniques. How shall it be interpreted? Is it an outcome of a profit-pursuit system of Japanese industries and the national economy? Is it because of an extreme lag in production techniques? Or, is it the result of unpreparedness in the research system in Japan?

Is it possible that a technique directly connected to profit without the burden of economic risk could be introduced easily here without preparation? In order that the introduced technique may really bear fruit, preliminary preparation must have been made of the technical base on which this technique should be carried out effectively. Probably, there are now many foreign techniques introduced in Japan that have achieved results as good or better than expected. In this case, it is necessary to be reminded that the preparedness for receiving these imported techniques has been perfect in every respect. This attitude of receiving an imported technique has not been built up over a short period. A certain technical base that has been adjusted over a long period of training for the same purpose or any other purpose presumably should have developed a natural ability to absorb newly introduced techniques from overseas. The research that may have appeared to have been roundabout surely has played a role.

In such cases, importation of overseas techniques is very effective and very significant for the improvement in the technical level of Japan. It should be considered, however, that at a time when the imported technique develops its effects, the technical level of the country which has exported it will be raised at a higher speed. It is not conceivable that any country should fall behind because of exporting its techniques.

Rationalization and development are proceeding in every field connected with liberalization of overseas trade. For the sake of achieving progress more effectively and more suitably, and also for the sake of a possible exportation of Japanese techniques, it is presumably necessary for Japan to adjust and to organize a consistent system of research from the aforementioned five stages as soon as possible. At present, there are a number of such research organizations in many fields in Japan that are performing research corresponding in content to respective stages (1) to (5) of the aforementioned process. The number of researchers involved is not small. Nevertheless, we do not consider that these organizations for iron and steel production have been organized on a concretely consistent system along the lines of technical research. We must point out that apparently they are performing studies independently and separately from their respective standpoints. For rapid progress of iron and steel production technique in Japan, the absolutely necessary measures are the establishment of a research system by way of organization of research institutions and the invigoration of research attitudes by means of preservation and development of economic factors and human resources. It is suggested that the Iron and Steel Institute of Japan should make further efforts for the accomplishment of such measures. 